Participatory Educational Research (PER)

Special Issue 2016-I, pp., 48-56; 01 January, 2016

Available online at http://www.partedres.com

ISSN: 2148-6123

http://dx.doi.org/10.17275/per.16.spi.1.6

\title{
Understanding Pronunciation Learning Strategy Use: a Vignette Analysis
}

\author{
Şakire ERBAY*, Mustafa Naci KAYAOĞLU and Eylül ÖNAY \\ Karadeniz Technical University, Trabzon, Turkey
}

\begin{abstract}
As is clear in the related literature, pronunciation is a neglected area in English language education throughout the world, and thus the area needs to be investigated so that informed decisions regarding pronunciation teaching could be taken. Hence, the present qualitative case study was designed to find out the strategies employed by the preparatory English majors chosen via convenience sampling $(n=56,44$ female and 12 male) in a middle-sized university in the north east part of Turkey. Inspired by Oxford's Strategy Game, eleven problem-oriented vignettes applicable for EFL context were devised and piloted. The fabricated vignettes include ten different areas: natural pronunciation, difficult and long words, self-confidence, misunderstanding, sounds not existing in Turkish, tone, sounds existing in native and target language, IPA knowledge, and intonation. The vignettes were quantified and interpreted on the basis of Rokoszewska's (2012) strategy taxonomy. The findings show that while cognitive metacognitive and memory strategies were frequently employed by the participants, social, compensation and affective ones were underused. The analysis also revealed that the participants used a wide variety of tactics in particularly cognitive strategies domain, including listening to tapes, music and watching TV/movie, pronouncing a difficult word over and over, memorising and practising target language sounds over and over, memorising and practising target language phrases, noticing mouth position or watching lips, practising listening, to list but a few. However, as language learning requires the development of not only cognitive and metacognitive but also emotional and interpersonal processes, it can be concluded that these underused strategies need to be promoted with strategy training and students' awareness need to be increased. Thus, the portrayal of pronunciation strategy use is expected to help material developers to integrate pronunciation learning strategies into newly devised instructional materials. The results are also expected to help teachers to take informed decisions about the instructional steps they take in their classrooms and plan strategy training.
\end{abstract}

Keywords: pronunciation, learning strategies, ELT, cognitive

\section{Introduction}

As is seen in the available literature, pronunciation teaching is a neglected aspect of language education in that it is either not integrated into language curriculum or not well joined together with the other language skills. Thus, Kelly (1969) compares pronunciation teaching to the tale of "Cinderella" (as cited in Celce-Murcia, Brinton \& Goodwin, 2010, p. 2) in that it is a neglected area of foreign language teaching. This may result from the fact that learning process is a long and daunting one with a wide variety of internal and external

\footnotetext{
* Corresponding author, Lecturer at Karadeniz Technical University, Milli Piyango Binası, A Blok A 103, Kanuni Kampüsü, telephone: 04623774235, e-mail: sakireerbay@ktu.edu.tr
} 
variables, including biology, cognition, psychology, and socio-cultural and pedagogical contexts of learning (Fang \& Li, 2012; Szyszka, 2015). Strategic learning in general and pronunciation learning in particular has gained popularity as one of the distinct features of successful language learning (Hismanoglu, 2012; Norton \& Toohey, 2001; Oxford, 1990). However, as Rose (2012) notes, the number of language learning strategy studies has decreased since the mid-1990s due to strategy taxonomy-related criticisms, data collection instruments, and contradictory findings.

The motivation of the researchers to conduct the present study is that more context-specific qualitative studies rather than the ones to be generalised across languages are needed, as argued by Rose (2012). In her own words, the use of qualitative data gathering instruments ensures "a richer picture of strategic learning than the quantitative instruments" (p. 143). Thus, in the present study 11 problem-based vignettes were used to gather in-depth qualitative data and provide a fuller picture of pronunciation language learning strategies in that the participants were supposed to write in detail what they would do in these hypothetical situations.

\section{Literature Review}

\section{Language Learning Strategies}

1990s witnessed a boom in strategy research with leading figures from strategy camp including Joan Rubin, O’Malley and Chamot and particularly Rebecca Oxford (Rose, 2012). Although learning strategies take various names such as learning skills, learning-to-learn skills, and problem solving skills, they refer to "specific actions taken by the learner to make learning easier, faster, more enjoyable, more self-directed, more effective, and more transferrable to new situations" (Oxford, 1990, p.8). As Table 1 shows, Oxford (1990), one of the leading figures from strategy camp, provides twelve features of learning strategies that could help understand the exact nature of learning strategies:

Table 1. Features of language learning strategies

\begin{tabular}{ll}
\hline \multicolumn{1}{c}{ Language learning strategies: } \\
\hline 1 & Contribute to the main goal, communicative competence. \\
2 & Allow learners to become more self-directed. \\
3 & Expand the role of teachers. \\
4 & Are problem-oriented. \\
5 & Are specific actions taken by the learner. \\
6 & Involve many aspects of learners, not just the cognitive. \\
7 & Support learning both directly and indirectly. \\
8 & Are not always observable. \\
9 & Are often conscious. \\
10 & Can be taught. \\
11 & Are flexible. \\
12 & Are influenced by a variety of factors.
\end{tabular}

Source: Oxford (1990, p. 9)

As summarised in the table above, learning strategies encourage learners to participate actively in interactions, and thus help the production of meaningful and contextualised language output. These strategies strengthen several aspects of communicative competence, including grammatical, sociolinguistic, discourse, and strategic elements. They also encourage learners to take the responsibility of their own learning, which leads to increased confidence, active participation, and high proficiency. Furthermore, they add variety to teachers' managerial and instructive roles in that they turn into facilitator, co-communicator, and consultant rather than hold a hierarchical authority, and both students and teachers feel successful when students take responsibility and learn much (Oxford, 1990). 
There is a great number of learning strategy taxonomies; however, Oxford (1990) is one of the most frequently referred scholars in the field with her two-level categorisation: direct and indirect strategies. Direct strategies are the ones that help learners deal with the new language, and they include memory, cognitive, and compensation strategies. However, indirect ones help learners manage learning in general and these are meta-cognitive, affective, and social ones. In Oxford's (1990) own words, “The direct class is composed of memory strategies for remembering and retrieving new information, cognitive strategies for understanding and producing the language, and compensation strategies for using the language despite knowledge gaps" (pp. 14-15). Similarly, she writes that the second group is composed of "metacognitive strategies for coordinating the learning process, affective strategies for regulating emotions, and social strategies for learning with others" (p. 15). According to the Oxford's taxonomy, memory strategies include creating mental linkages, applying images and sound, reviewing well, and employing action while the cognitive category includes practising, receiving and sending messages, analysing and reasoning, and creating structure for input and output. The last direct strategy category, i.e., compensation strategies, includes examples such as guessing intelligently and overcoming speaking and writing-related limitations. On the other hand, metacognitive strategies include centering learning, arranging and planning it, and evaluating it. Affective strategies focus on lowering anxiety, encouraging oneself, and taking emotional temperature. Lastly, social strategies include examples such as asking questions, cooperating with others, and empathising with others.

\section{An Overview of Pronunciation Teaching, Learning and Strategies}

The rise of Audio-lingualism and the Direct Method was a major factor that ignited the popularity of pronunciation instruction in the language classroom before the 1960s. However, pronunciation was marginalised particularly between 1960s and the late 1970s due to three reasons. First, scholar questioned the practice of habit formation as meaning and context were ignored in the process. Second, the Critical Period Hypothesis and the Cognitive Approach discouraged non-native English learners with their emphasis on the impossibility of attaining native-like pronunciation. Third, the focus of Krashen's Input Hypothesis on input rather than output decreased the popularity of speaking in language classrooms. However, later in the 1980s, pronunciation instruction started to be popular again due to the advent of the Communicative Approach, and since then the need for pronunciation has become urgent due to the increasing number of non-native speakers of English who need to become intelligible language users (Celce-Murcia, Brinton \& Goodwin, 2010; Chang, 2012).

Pronunciation instruction and strategies have been also welcome due to the growing attention to the concept of learner autonomy (Chang, 2012). As Richards and Schmidt (2002) describe, learner autonomy in language teaching is "the principle that learners should be encouraged to assume a maximum amount of responsibility for what they learn and how they learn it" (p. 297). As this sense of responsibility is associated with effective learning, teachers are suggested to equip their students with strategies, which can result in more active and more independent language learners whom are expected "to make more progress in the long run if they continued practising on their own" (Chang, 2012, p. 7).

\section{Earlier Studies}

Particularly, several studies have been conducted to create taxonomy for pronunciation learning strategies. One of the earliest one belongs to Peterson (2000), who conducted a diary and interview study to investigate pronunciation learning strategies used by 11 Spanish learners. The findings showed that cognitive strategies were favoured most, and 
memory, compensation, and affective strategies were preferred least. Based on her findings and Oxford's (1990) strategy categorisation, she created a categorisation including the following strategies: representing sounds in memory (memory); practising naturalistically, formally practising with sounds, and analysing the sound system (cognitive); using proximal articulation (compensation); finding out about target language pronunciation, setting goals and objectives, planning for a language task, and self-evaluating (metacognitive); using humour to lower anxiety (affective); and asking for help and cooperating with peers (social).

In addition to Peterson, there is a number of similar pronunciation learning strategy taxonomies including Eckstein's (2007) proposal associated with Kolb's (1984) Experiential Learning Theory, Pawlak's (2010) categorisation (cited in Chang, 2012, pp 21-22), to list but a few. As Chang (2012) clearly puts it, the documentation and classification of pronunciation learning strategies is vital as these attempts help the others extend their knowledge of pronunciation learning strategies.

Several other studies have been conducted to investigate pronunciation learning strategy use. One which inspired the present study belongs to Rokoszewska (2012), who conducted a questionnaire study with first-grade English majors. She adapted Calka's (2011, cites in Rokoszewska, 2012, p.393) Pronunciation Learning Strategies Questionnaire, which also served well for the content analysis of students' answers for the vignettes in the present study. In general the participants were found to use more indirect strategies than the direct ones, and the use of metacognitive strategies was the highest. Yet, as far the direct ones, the use of cognitive strategies with a wide variety of tactics such as reading aloud, talking to oneself in target language, doing transcription, listening to recordings, repeating after target language speakers, doing phonetic drills, and acting out dialogues was found to be highest. Rokozewska (2012) concludes that students may benefit from strategy-based instruction in their pronunciation courses.

The importance of pronunciation learning strategies has not gone unnoticed in Turkey, too although the research field is in its early stages of development. Among Turkish scholars interested in the issue, Hişmanoğlu (2012) conducted a study with 38 English majors in Cyprus to find out possible differences between the pronunciation strategy use of successful and unsuccessful learners. He found that advanced student tended to use more metacognitive strategies in general and self-evaluation as a tactic of it. The findings also showed that a great number of the participants stated that they employed affective strategies including the use of humour to lower anxiety and the development of humour about their own mispronunciation. However, the use of social strategies with tactics such as asking for help, cooperating with peers, asking somebody else to correct them and pronounce a word, and tutoring others was found to be the least. In general, it was found that advanced English as a Foreign Language students tended to employ all six major strategies although the use of metacogntive, affective and compensation ones was the highest. The least frequently used ones were social strategies.

There are some more related studies conducted in Turkish context that aimed at investigating pronunciation strategy use of Turkish English language learners. For instance, in a study conducted with a strategy inventory and two pronunciation elicitation tasks, Berkil (2008) aimed at investigating English majors' strategy use and found that female learners employed ore strategies. Contrary to several parallel studies, while the mostly employed strategy was affective ones, metacognitive strategies were the least frequently used ones. In another study Akyol (2013) aimed at investigating pronunciation strategy use of prospective teachers with a questionnaire and seeing whether a pronunciation course could make a difference between 
students. Different form the existing literature, Akyol (2013) found that cooperation strategies, i.e., social ones, were highly employed, and memory and affective ones followed them. On the other hand, the least used ones were compensation, metacognitive, and cognitive pronunciation learning strategies.

\section{Methodology}

The current qualitative case study was designed to further the existing works by documenting tertiary level students' pronunciation learning strategies. Thus, the research question of what strategies English majoring students use to improve their learning guided the whole process. Case study research design was opted for as "with a case study, the case is an object of interest in its own right and the researcher aims to provide an in-depth elucidation of it" (Bryman, 2004, p. 50). As the aim was not to generalise findings that could be applied regardless of time and place but to find out the unique features of one department a single case, the study was designed as a case study.

\section{Setting and Participants}

The study was conducted at the department of Western Languages and Literature of a mid-size university in the northeast part of Turkey. The department has a four-year English medium education in addition to its one-year compulsory preparatory training. The reason behind the choice of setting is that two of the researchers have been working as instructors in that institution while one is a Bachelor of Arts student at the department. This collaboration is regarded as vital, for the instructors' pronunciation teaching experience and observation could help them generate a more intensive examination while the student researcher's stance could help them all create data gathering instrument and interpret the findings from taking a real student's point of view into consideration.

A total number of 56 preparatory programme female $(\mathrm{N}=44)$ and male $(\mathrm{N}=12)$ students took part in the current study. Convenience sampling was preferred to choose the participants as non-probability sampling is regarded more appropriate for qualitative research. As Ritchie, Lewis and Elam (2003) put it, neither statistical representations nor scales play a key role in qualitative research, and it "does not set out to estimate the incidence of phenomena in the wider population" (p. 81), the researchers chose the participants based on ease of access. The participants coming from various cities of Turkey have various education backgrounds, and they take several courses on basic English skills, literature, culture, and linguistics.

\section{Instruments and Procedure}

To gain a further understanding of pronunciation learning strategies, the present study employed vignettes as a data gathering instrument, which is believed to add to its originality as none of the previous studies used it to gather their data. Inspired by Oxford's (1990) Strategy Research Game, the researchers devised 11 problem-oriented vignettes applicable for EFL contexts. These hypothetical situations include ten different problem areas: natural pronunciation, difficult and long words, self-confidence, misunderstanding, sounds not existing in Turkish, tone, sounds existing in native and target language, IPA knowledge, and intonation.

The vignettes were piloted with 10 evening class preparatory students (non-participants) and 1 expert for item clarity. The participating students were given the Turkish versions of the vignettes and asked to write their answers in Turkish in the presence of the researchers in a 
comfortable and familiar classroom atmosphere. As an example, the fourth vignette given below aimed at finding out the pronunciation strategies used to avoid pronunciation mistakes that cause misunderstanding and result in communication breakdowns:

Imagine that you were a preparatory programme student at a department of English language and literature. You were supposed to prepare an oral presentation for your speaking class. In that presentation you were supposed to lecture your classmates as if you were their teacher. You started the class with the following sentence: "Now /nav/ I /al/ will /wil/ give /giv/ you /ju/ some /sam/ sheets /i:ts /". Your friends started to laugh at you, and your concentration broke. As a consequence you did not want to continue any more. Your mispronunciation caused communication breakdown. What would you do to avoid such problems?

Content analysis was employed to analyse the participants' answers. Bryman (2004) defines content analysis as "an approach to the analysis of documents and texts that seeks to quantify content in terms of predetermined categories and in a systematic and replicable manner" (p. 183). In the present study, the questionnaire items used by Rokoszewska (2012) which was composed by Calka (2011) based on Oxford's (1990) categorisation of language learning strategies were used as the predetermined categories to analyse the participants' answers to the vignettes. In this way, it was expected that the participants' qualitative answers could be analysed both objectively and systematically.

\section{Findings and Discussion}

\section{The Use of Pronunciation Learning Strategies in General}

The answers of the participants to all eleven vignettes were analysed and classified based on the predetermined categories used by Rokoszewska (2012). Table 2 shows the general pronunciation strategy use tendency of the participating students.

Table 2. General tendency of pronunciation strategy use based on Oxford's (1990)

\begin{tabular}{lcl}
\multicolumn{3}{c}{ categorisation } \\
\hline Strategy Categorisation & Female (f) & Male (f) \\
\hline Cognitive & $609(58.8 \%)$ & $134(56.5 \%)$ \\
Metacognitive & $219(21.1 \%)$ & $45(18.9 \%)$ \\
Memory & $117(11.3 \%)$ & $26(10.9 \%)$ \\
Social & $72(6.9 \%)$ & $26(10.9 \%)$ \\
Compensation & $9(0.8 \%)$ & $4(1.6 \%)$ \\
Affective & $8(0.7 \%)$ & $2(0.8 \%)$ \\
TOTAL & $1034(100 \%)$ & $237(100 \%)$ \\
\hline
\end{tabular}

The results of the content analysis of the answers given to the hypothetical situations show that the participants involved in the study highly employed cognitive strategies at the $58.8 \%$ level (for females) and $56.5 \%$ (for males). The second highest popular strategies were metacognitive one, and they were followed by memory, social, compensation, and affective ones. The least favoured strategies that belong to the indirect strategy group of Oxford's (1990) classification were affective ones in both female and male groups. These findings are in tune with several other study findings including Peterson (2000) and Rokoszewska (2012), who found a high frequency employment of cognitive strategies with a wide variety of tactics. However, the present findings are contrary to the findings of Berkil (2008), who documented a highest use of affective strategies and the lowest use of metacognitive ones. The results do not also concur with the findings of Akyol (2013), who found a high use of social strategies and a low use of metacognitive and cognitive ones. Lastly, these findings do not confirm with 
the findings of Hişmanoğlu (2012), who found out that advanced EFL learners mostly employ first affective and then metacognitive pronunciation learning strategies.

\section{Strategy Use per Vignette}

As the table above shows, the participating students generally tended to use cognitive and metacognitive strategies to avoid possible problems in pronunciation. The answers given to all vignettes were also analysed in a detailed way to see strategy preferences for each problem area such as the pronunciation of difficult and long words, difficult sounds that do not exist in Turkish, to list but a few. Table 3 illustrates strategy use tendency per vignette.

Table 3. Strategy use per vignette

\begin{tabular}{|c|c|c|c|c|c|c|c|c|c|c|c|}
\hline Strategy & 1. & 2. & 3. & 4. & 5. & 6. & 7. & 8. & 9. & 10. & 11. \\
\hline & Vignette & & & & & & & & & & \\
\hline & $\begin{array}{l}\text { Female/M } \\
\text { ale }\end{array}$ & F/M & F/M & F/M & F/M & F/M & F/M & F/M & F/M & F/M & F/M \\
\hline Memory & $10 / 4$ & $19 / 5$ & $12 / 2$ & $21 / 1$ & $8 / 6$ & $3 / 0$ & $3 / 0$ & $19 / 5$ & $3 / 0$ & $3 / 1$ & $4 / 2$ \\
\hline Cognitive & $47 / 11$ & $55 / 11$ & $74 / 19$ & $18 / 7$ & $61 / 14$ & $71 / 10$ & $49 / 3$ & $49 / 7$ & $57 / 12$ & $74 / 18$ & $54 / 22$ \\
\hline Compen. & $0 / 1$ & $2 / 2$ & $0 / 0$ & $2 / 0$ & $0 / 0$ & $0 / 0$ & $0 / 1$ & $0 / 0$ & $2 / 0$ & $1 / 0$ & $2 / 0$ \\
\hline Metacognt. & $28 / 5$ & $17 / 1$ & $16 / 6$ & $23 / 6$ & $23 / 5$ & $29 / 6$ & $10 / 4$ & $22 / 4$ & $20 / 2$ & $12 / 4$ & $19 / 2$ \\
\hline Affective & $1 / 0$ & $1 / 0$ & $1 / 0$ & $1 / 1$ & $1 / 1$ & $2 / 0$ & $0 / 0$ & $0 / 0$ & $0 / 0$ & $0 / 0$ & $1 / 0$ \\
\hline Social & $9 / 3$ & $5 / 2$ & $9 / 2$ & $3 / 2$ & $7 / 2$ & $2 / 3$ & $3 / 2$ & $8 / 1$ & $9 / 2$ & 474 & $13 / 3$ \\
\hline TOTAL & $95 / 24$ & $99 / 21$ & $112 / 29$ & $68 / 17$ & $99 / 28$ & $107 / 19$ & $65 / 10$ & $98 / 17$ & $91 / 16$ & $94 / 27$ & $93 / 40$ \\
\hline
\end{tabular}

As the table above clearly indicates, cognitive, metacognitive, and memory strategies were the highly employed ones in each hypothetical situation, i.e., eleven vignettes. For instance, in the first vignette, while the female participants were found to use cognitive strategies for 47 times, their male counterparts employed them for 11 times. As far as affective strategies as one type of indirect pronunciation learning strategies are concerned, the participant either used them rarely, i.e., once, or never.

\section{The Most Frequently Used Tactics}

The analysis of the vignettes has shown that the participating students used several tactics, i.e., sub-categories/sub-sets under the general pronunciation learning strategies. The following table shows the most frequently preferred tactics under each six category.

Table 4. The most frequently employed tactics

\begin{tabular}{ll}
\hline Strategies & Tactics \\
Cognitive & Memorising and practising phrases \\
& Concentrating intensely on pronunciation while listening \\
& Noticing mouth positions and watching lips \\
& Talking to oneself loudly \\
& Writing words with IPA over and over \\
& Practising listening \\
Metacognitive & Reading and using reference materials about rules (dictionary, Internet, etc.) \\
& Recording oneself to listen to one's own pronunciation \\
Memory & Seeking for practice opportunities \\
& Making notes: creating cards, games, vocabulary lists with transcriptions \\
Social & Using phonetic symbols or one's own codes to remember how to pronounce something \\
& Studying with peers or advanced users of TL including the teacher \\
Compensation & Asking someone else to pronounce something \\
& Asking someone else to correct one's own pronunciation \\
Avoiding words whose pronunciation is difficult and long & Trying to guess the pronunciation of words \\
& Having a sense of humour about mispronunciation \\
& Motivating oneself \\
\hline
\end{tabular}


As the table above shows, in the category of cognitive and metacognitive strategies, a wide variety of tactics were identified. The participants stated that they would make a greater use of cognitive tactics that "involve direct learning and use of the subject matter" (Oxford, 1990, p.11) such as memorising and practising phrases, concentrating intensely on pronunciation while listening, watching and noticing both the mouth and lip positions of the speaker, talking to themselves loudly, and practising listening. The results also show that the participants highly tended to employ metacognitive tactics that "contribute indirectly but powerfully" (Oxford, 1990, p.12) to the process of their language learning including making use of reference materials such as dictionary, the Internet, and etc., recording themselves to listen to their own pronunciation, and searching for pronunciation practice opportunities. However, in the other less used general strategy categories including memory, social, compensation, and affective, less variety was found. While the ones that reported to use memory strategies wrote that they would make notes and use phonetic symbols to remember correct pronunciation, the ones using social strategies remarked that they would collaborate with their peers and ask the help of more advanced ones to provide them with the correct pronunciation of words and to correct their own mistakes. Most of the participants referred to their teacher as the advanced individual with whom they would like to collaborate and for whom they would ask help. As for the compensation strategies, the participants reported that they would avoid the words that have long and difficult pronunciation and they would try to guess the pronunciation of words. Lastly, the least variety was found in affective tactics in that the participants stated that they would laugh at their own mistakes and motivate themselves in these hypothetical problematic situations.

Overall, the results of the study indicated that the preparatory programme students of the English language and literature department use more of cognitive strategies as direct ones and metacognitive strategies as the indirect ones. The tactic variety is in parallel with frequency of strategy use in that the participants reported that they relied to a great extent on a wide variety of cognitive tactics. However, they neglected the use of affective, compensation, and social strategies. As rightly put by Rokoszewska (2012), this preference of the participants could be partially explained with the fact that they have been thought mostly with cognitive activities and tasks in the formal classroom practice, and thus they need to be informed about the other less preferred strategy categories and their possible benefits.

\section{Conclusion}

The aim of the present study was not to provide fixed answers about strategy employment but to further related studies with its contribution to food for thought. It was found that while cognitive, metacognitive, and memory strategies were highly employed, social, compensation, and affective ones were underused. However, as Oxford (2012) rightly remarks, "language learning is indisputably an emotional and interpersonal process as a well as a cognitive and metacognitive affair" (p. 11). Hence, a wide variety of pronunciation strategies and tactics need to be promoted in language classrooms. The findings could serve well to support some implications useful to better inform pronunciation instruction process. As Oxford (1990) puts it, assessing students' strategy use can be helpful for teachers to facilitate the learning process and for learners to tackle with language tasks successfully and have improved learning outcome as "conscious skill in self-directed learning and in strategy use must be sharpened through training" (p. 201). In addition to promoting these underused strategies with strategy training, the awareness of instructional material developers needs to be increased so that they can integrate a wide variety pronunciation learning strategies and tactics that go beyond cognitive domain into newly devised instructional materials. The results are also expected to 
help teachers to take informed decisions about the instructional steps they take in their classrooms and plan their classroom activities that could help them promote learner autonomy.

What seems to be worth of note is that the present study is not without its limitation. As Rose (2012) highlights, over-generalisation of study findings in strategy research is problematic as "it is time to explore each learning context with the complexity it deserves" (p. 146). Thus, rather than over generalising the findings the present study calls attention to the need to design strategy training activities that can encourage learners to employ a variety of strategies and to the need to integrate awareness raising and learner autonomy promoting activities in language teaching materials. These practices are invaluable in that as Fang and Lin (2012) rightly put, in non-native language learning contexts, teachers themselves may lack the sufficient pronunciation knowledge, which in turn attaches particular urgency to learners' manipulation of their own learning process.

\section{References}

Akyol, T.(2012). A study on identifying pronunciation learning strategies of Turkish EFL learners. Procedia-Social and Behavioral Sciences, 70, 1456-1462.

Berkil, G. (2008). A closer look at pronunciation learning strategies, L2 pronunciation proficiency and speaking variables influencing pronunciation ability. Unpublished MA Thesis, Bilkent University.

Bryman, A. (2004). Social research methods. 2nd ed. Oxford: Oxford University Press.

Celce-Murcia, M., Brinton, D. M., \& Goodwin, J. M. (2010). Teaching pronunciation: A course book and reference guide. ( $2^{\text {nd }}$ ed.). New York: Cambridge University Press.

Chang, C-H. (2012). Instruction on pronunciation learning strategies: Research findings and current pedagogical approaches. Unpublished MA Thesis, The Faculty of Graduate School, The University of Texas at Austen.

Fang, T., \& Lin, C-C. (2012). Taiwan EFL learners' pronunciation strategies in two learning contexts. Journal of Language Teaching and Research, 3(5), 888-897.

Hismanoglu, M. (2012). An investigation of pronunciation learning strategies of advanced EFL learners. Hacettepe University Journal of Education, 43, 246-257.

Norton, B., \& Toohey, K. (2001). Changing perspectives on good language learners. TESOL Quarterly, 35 (2), 307-322.

Oxford, R. L. (1990). Language learning strategies: What every teacher should know. Boston: Heinle \& Heinle Publishers.

Peterson, S. S. (2000). Pronunciation learning strategies: A first look. Unpublished research report. (ERIC Document Reproduction Service ED 450 599; FL 026 618).

Richards, J. C., \& Schmidt, R. (2002). Longman dictionary of language teaching and applied linguistics. London: Pearson Education Limited.

Ritchie, J., Lewis, J., \& Elam, G. (2003). Designing and selecting samples. In J. Ritchie and J. Lewis (eds), Qualitative research practice: A guide for social students and researchers (pp. 77-108). London: Sage Publications.

Rokoszewska, R. (2012). The influence of pronunciation learning strategies on mastering English vowels. Studies in Second Language Learning and Teaching, 2(3), 391-413.

Rose, H. (2012). Language learning strategy research: Where do we go from here? Studies in Self-access Learning Journal, 3(2), 137-148.

Szyska, M. (2015). Good English pronunciation users and their pronunciation learning strategies. Research in Language, 13 (1), 93-106. 